\title{
Espécies nativas de plantas frutíferas em uma área de Cerrado em Mato Grosso, Brasil
}

\author{
Native species of fruit trees in an area of Cerrado in Mato Grosso, Brazil \\ Nadja Gomes Machado',2, Bruna Gonçalves Aquino', \\ Guilherme Araújo Pessoa Contúrbia Neves ${ }^{3}$ \\ ' 'Laboratório de Biologia da Conservação, Instituto Federal de Mato Grosso, Cuiabá, MT, Brasil \\ ${ }^{2}$ Programa de Pós-graduação em Física Ambiental, Universidade Federal de Mato Grosso, Cuiabá, MT, Brasil \\ ${ }^{3}$ Instituto de Biociências, Universidade Federal de Mato Grosso, Cuiabá, MT, Brasil
}

\begin{abstract}
Resumo
O Cerrado é o segundo maior bioma brasileiro, composto por savanas, matas, campos e matas de galeria com mais de 7 mil espécies de plantas, com $44 \%$ endêmicas. O objetivo deste trabalho foi identificar as espécies de plantas frutíferas de Cerrado na área do Campus São Vicente do IFMT e seu potencial de uso alimentar, medicinal e de outros tipos. O campus está localizado em $15^{\circ} 49^{\prime} \mathrm{S}$ e $55^{\circ} 25^{\prime} \mathrm{O}$, distante $86 \mathrm{~km}$ de Cuiabá/MT. A coleta de dados ocorreu entre maio e junho de 2010 com localização e identificação das plantas frutíferas na área denominada de Agri3. Foram encontrados 184 indivíduos distribuídos em 20 espécies e 14 famílias. As espécies Acrocomia aculeata e Anacardium humile apresentaram 48 e 47 indivíduos, respectivamente. Enquanto que, as espécies Mouriri elliptica, Brosimum gaudichaudii, Genipa americana, Talisia esculenta e Vitex montevidensis apresentaram apenas 01 indivíduo cada. Das 20 espécies, 07 apresentam usos na alimentação, medicinal e outros; enquanto que 01 apresentou apenas uso alimentar e medicinal; e, 05 apresentam somente uso alimentar. A vegetação é um recurso fundamental para alimentação humana, assim como sua exploração comercial pode propiciar desenvolvimento socioeconômico através de extrativismo ordenado ou plantação das espécies, podendo acarretar em políticas públicas de conservação das espécies.
\end{abstract}

Palavras-chave: Plantas nativas, conservação, uso alimentar, uso medicinal, São Vicente da Serra.

\begin{abstract}
The Cerrado is the second largest biome consists of savannas, woodlands, grasslands and riverine forests with more than 7,000 plant species, in which $44 \%$ are endemic. The aim of this study was to identify the species of fruit plants of Cerrado in the São Vicente Campus and its potential use for food, medicine and other types. The campus is located at $15^{\circ} 49^{\prime} \mathrm{S}$ and $55^{\circ} 25^{\prime} \mathrm{O}$, distant $86 \mathrm{~km}$ from Cuiabá/MT. Data was obtained between May and June 2010 with location and identification of fruit plants in the area called Agri3. 184 individuals belonging to 20 species and 14 families were found. The aculeata Acrocomia and Anacardium humile species were 48 and 47 individuals, respectively. While the species Mouriri elliptica, Brosimum gaudichaudii, American Genipa, Talisia esculenta and Vitex montevidensis showed only 01 individuals each. Of the 20 species, 07 have been used for food, medical and other uses, while 01 showed only food and medicinal uses, and 05 have only 05 food use. The vegetation is a key feature for human consumption, as well as its commercial exploitation can promote socioeconomic development through wages or planting species extraction that can result in public policies for species conservation.
\end{abstract}

Keywords: Native plants, conservation, food use, medicinal use, São Vicente da Serra. 


\section{INTRODUÇÃO}

O Cerrado é o segundo maior bioma brasileiro, ocupando originalmente quase 2 milhões de $\mathrm{km} 2$ (Ratter et al. 1997). Ele é um mosaico composto por savanas, matas, campos e matas de galeria, que ocupa 23\% do território brasileiro (Klink e Machado 2005). Este bioma tem um clima caracterizado por estações de chuva e seca bem definidas, com temperaturas que variam entre 18 e $28^{\circ} \mathrm{C}$ e precipitação entre 800 e $2000 \mathrm{~mm}$ anuais (Ratter et al. 1997). Seu solo é, predominantemente, antigo, intemperizado e ácido (Klink e Machado 2005). Há, aproximadamente, 7 mil espécies de plantas (Castro et al. 1999), onde 44\% são endêmicas (Klink e Machado 2005).

Shiki et al. (1997) enfatizam que o cerrado brasileiro apresenta uma biodiversidade que oferece distintas possibilidades de aproveitamento sustentável. A abordagem sobre a utilização dos recursos vegetais em áreas do Cerrado, bem como a sua manutenção e conservação são discutidas na literatura por Siqueira (1981), Macedo (1991), Ribeiro et al. (1992), Brandão (1992), Almeida \& Silva (1994), Silva et al. (1994), Paula \& Alves (1997), Almeida et al. (1998), Proença et al. (2000), Guarim Neto (2001), Pasa et al. (2005). Os referidos autores tem oferecido uma contribuição valiosa, enfocando cerrados brasileiros de áreas geográficas diversas, bem como a relação que se estabelece entre populações humanas e os recursos ambientais.

No entanto, nos últimos 30 anos, aproximadamente, 1,783 milhões de $\mathrm{km}^{2}$ do Cerrado sofreram severos impactos antrópicos (Jepson 2005), diretamente causados pela retirada da vegetação nativa por causa da expansão e da modernização da agricultura (Ratter et al. 1997). A conversão do Cerrado em sistemas simplificados provoca severas alterações nos habitats aquáticos (Wantzen et al. 2006), bem como na estrutura trófica das comunidades terrestres. Portanto, estudos sobre sua estrutura, funcionamento e conservação são fundamentais.

A vegetação é um recurso fundamental para alimentação humana, assim como sua exploração comercial pode propiciar desenvolvimento socioeconômico através de extrativismo ordenado ou plantação das espécies o que pode acarretar em políticas públicas de conservação. Vale ressaltar que, as plantas frutíferas do Cerrado são pouco estudadas. Embora, já seja sabido, em função das pesquisas desenvolvidas pela EMBRAPA Cerrado, o potencial de plantas frutíferas do Cerrado. O objetivo desta pesquisa foi identificar as espécies de plantas frutíferas de Cerrado na área do Campus São Vicente do IFMT e seu potencial de uso alimentar, medicinal e de outros tipos.

\section{MATERIAL E MÉTODOS}

\section{1 Área de Estudo}

Este estudo foi desenvolvido em uma área de Cerrado no Campus São Vicente (Coordenadas Geográficas $15^{\circ} 49^{\prime}$ S e $55^{\circ} 25^{\prime} \mathrm{O}$ ), do Instituto Federal de Mato Grosso (IFMT) no município de Santo Antônio de Leverger - MT, distante $86 \mathrm{~km}$ de Cuiabá/MT (Figura 1). O solo da área foi classificado como LATOSSOLO VERMELHO distrófico típico. O clima é de transição entre Cwa e Cwb segundo Köppen, com temperatura média anual de $23,3^{\circ} \mathrm{C}$ e precipitação pluviométrica média anual de 2.007 $\mathrm{mm}$ (Roboredo et al. 2010).

\subsection{Coleta de Dados}

A coleta de dados se consistiu em localização e identificação das plantas frutíferas na área do Campus São Vicente do Instituto Federal de Mato Grosso (1549'12,34' S e 55²5’5,11' O), em Santo Antônio do Leverger, Mato Grosso (Figura 1). As informações coletadas sobre as plantas foram: localização (coordenadas geográficas), espécie, presença de frutos, presença de flores, pesquisador e outras observações relevantes. As idas a campo ocorreram entre maio e junho de 2010.

\section{RESULTADOS E DISCUSSÃO}

Nós encontramos 184 indivíduos distribuídos em 20 espécies e 14 famílias, sendo 03 (três) espécies da família Arecaceae, 02 (duas) espécies das famílias Annonaceae, Fabaceae e Solanaceae e, para as demais apenas 01 (uma) espécie. As espécies Acrocomia aculeata e Anacardium humile apresen- 


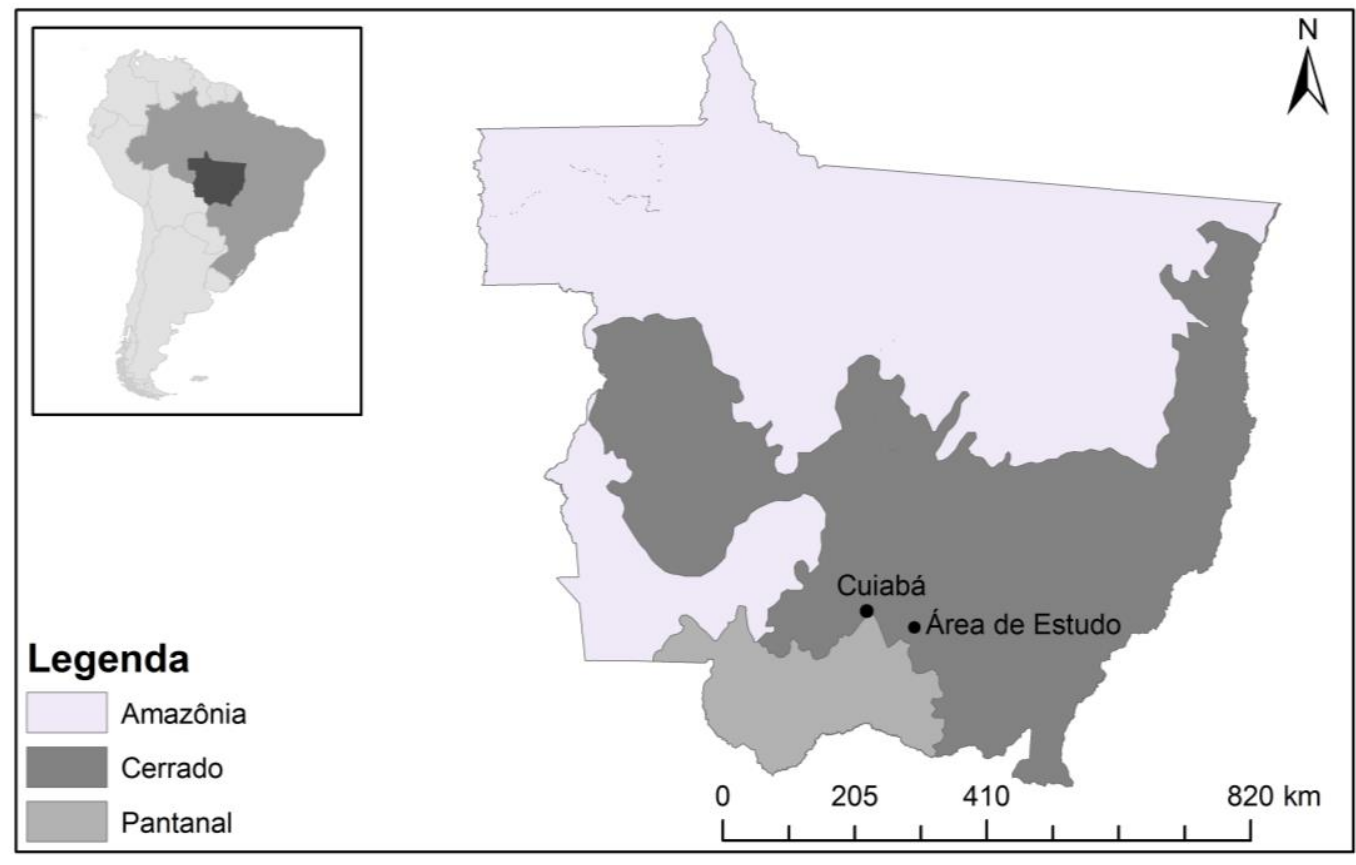

Figura 1 - Localização da área de estudo no bioma Cerrado em Mato Grosso.

Tabela 1. Espécies nativas de plantas frutíferas e número de indivíduos encontrados em uma área de Cerrado em Mato Grosso, 2010.

\begin{tabular}{lllc}
\hline Família & Nome Científico & Nome Popular & Abundância absoluta \\
\hline Anarcadiaceae & Anacardium humile & Cajuzinho-do-mato & 47 \\
Annonaceae & Annona sp. & Araticum & 5 \\
& Anonna crassiflora & Araticum & 6 \\
& Orbignya sp. & Babaçu & 15 \\
Arecaceae & Scheelea phalerata & Bacuri & 20 \\
& Acrocomia aculeata & Bocaiúva & 48 \\
Bromeliaceae & Bromelia balansae & Gravatá & 3 \\
Caryocaraceae & Caryocar brasiliense & Pequi & 2 \\
Ebenaceae & Diospyros burchellii & Olho-de-boi & 4 \\
& Dipteryx alata & Cumbaru & 2 \\
Fabaceae & Inga edulis & Ingá-de-metro & 3 \\
& Hymenaea stigonocarpa & Jatobá & 3 \\
Melastomataceae & Mouriri elliptica & Croadinha & 1 \\
Moraceae & Brosimum gaudichaudii & Mama-cadela & 1 \\
Rubiaceae & Genipa Americana & Jenipapo & 1 \\
Sapindaceae & Talisia esculenta & Pitomba & 1 \\
Solanaceae & Solanum paniculatum & Jurubeba & 12 \\
Sterculiaceae & Solanum lycocarpum & Lobeira & 7 \\
Verbenaceae & Guazuma tomentosa & Chico magro & 2 \\
\hline
\end{tabular}

taram 48 e 47 indivíduos, respectivamente (Tabela 1).

As espécies Scheelea phalerata e Orbignya sp. apresentaram 20 e 15 indivíduos, respectivamente. Enquanto que, as espécies Mouriri elliptica, Brosimum gaudichaudii, Genipa americana, Talisia esculenta e Vitex montevidensis apresentaram apenas 01 indivíduo cada.

Do total observado, $48 \%$ apresentaram ausência de flor e frutos, $31 \%$ presença de fruto, $17 \%$ fruto e $4 \%$ apenas flor (Figura 2 ). 


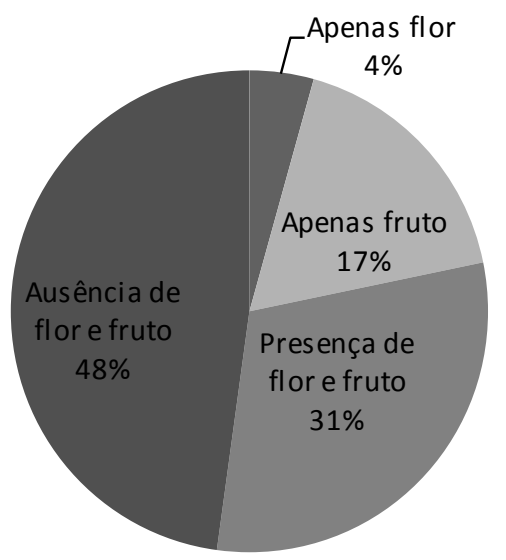

Figura 2 - Porcentagem de indivíduos com presença e/ou ausência de flor e/ou fruto nas espécies nativas de plantas frutíferas em uma área de Cerrado em Mato Grosso, 2010.

Tabela 2 - Comparação entre os resultados deste estudo e a literatura sobre a floração e frutificação das espécies nativas de plantas frutíferas em uma área de Cerrado em Mato Grosso, 2010.

\begin{tabular}{|c|c|c|c|c|}
\hline $\begin{array}{l}\text { Nome } \\
\text { científico }\end{array}$ & Floração & Frutificação & Fonte & Comparação \\
\hline A. aculeata & Setembro a janeiro & Outubro a dezembro & Pott \& Pott 1994 & Diferente \\
\hline A. humile & Julho a setembro & Agosto a setembro & $\begin{array}{l}\text { Lorenzi et al. } \\
2006\end{array}$ & Semelhante \\
\hline A. crassiflora & Setembro a janeiro & Outubro a abril & $\begin{array}{l}\text { Silva Junior } \\
2005\end{array}$ & Diferente \\
\hline B. balansae & Setembro a fevereiro & Outubro a abril & Pott \& Pott 1994 & Semelhante \\
\hline $\begin{array}{l}\text { B. } \\
\text { gaudichaudii }\end{array}$ & Julho a novembro & Julho a dezembro & $\begin{array}{l}\text { Silva Junior } \\
2005\end{array}$ & Semelhante \\
\hline C. brasiliense & Julho a janeiro & Outubro a fevereiro & $\begin{array}{l}\text { Silva Junior } \\
2005\end{array}$ & Semelhante \\
\hline D. burchellii & Julho a outubro & Novembro a julho & $\begin{array}{l}\text { Silva Junior } \\
2005\end{array}$ & Semelhante \\
\hline D. alata & $\begin{array}{l}\text { Novembro a } \\
\text { fevereiro }\end{array}$ & Janeiro a março & $\begin{array}{l}\text { Silva Junior } \\
2005\end{array}$ & Semelhante \\
\hline G. Americana & Setembro a dezembro & Outubro a fevereiro & Pott \& Pott 1994 & Semelhante \\
\hline G. tomentosa & Setembro a março & Maio a setembro & Pott \& Pott 1994 & Semelhante \\
\hline H. stigonocarpa & Outubro a abril & Abril a julho & $\begin{array}{l}\text { Silva Junior } \\
2005\end{array}$ & Diferente \\
\hline I. edulis & Outubro a janeiro & Não encontrado & $\begin{array}{l}\text { Lorenzi et al. } \\
2006\end{array}$ & Diferente \\
\hline M. elliptica & $\begin{array}{l}\text { Setembro a dezembro } \\
\text { (quase todo o ano) }\end{array}$ & $\begin{array}{l}\text { Dezembro a março } \\
\text { (quase todo o ano) }\end{array}$ & Pott \& Pott 1994 & Semelhante \\
\hline S. phalerata & Junho a outubro & Quase todo o ano & Pott \& Pott 1994 & Semelhante \\
\hline S. lycocarpum & Todo o ano & Março a julho & $\begin{array}{l}\text { Silva Junior } \\
2005\end{array}$ & Semelhante \\
\hline S. paniculatum & Outubro a janeiro & Dezembro a março & Pott \& Pott 1994 & Diferente \\
\hline T. esculenta & Agosto a outubro & Janeiro a março & $\begin{array}{l}\text { Lorenzi et al. } \\
2006\end{array}$ & Semelhante \\
\hline $\begin{array}{l}V . \\
\text { montevidensis }\end{array}$ & Outubro a dezembro & Novembro a janeiro & $\begin{array}{l}\text { Lorenzi et al. } \\
2006\end{array}$ & Semelhante \\
\hline
\end{tabular}




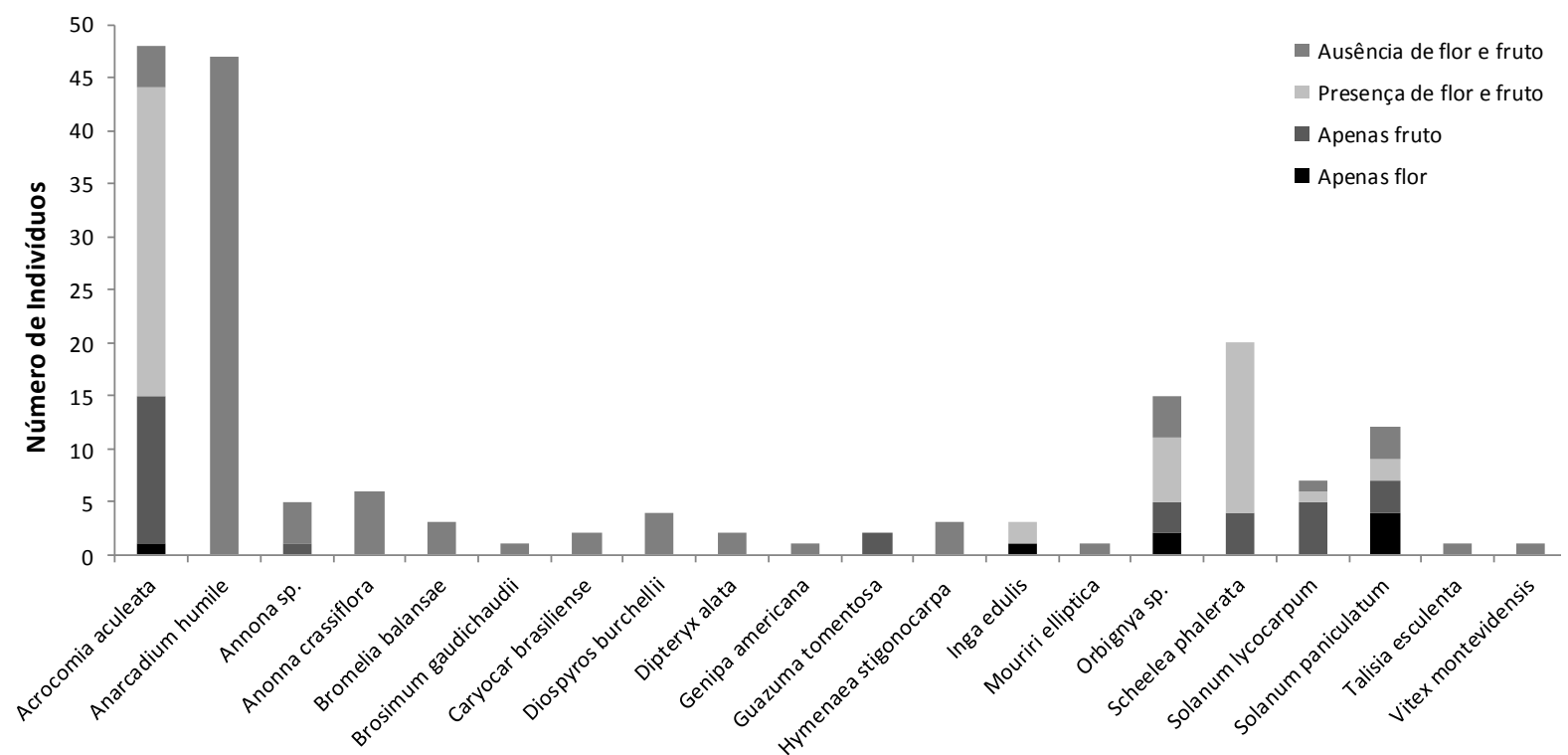

Figura 3 - Presença e/ou Ausência de flor e/ou fruto nos indivíduos das espécies nativas de plantas frutíferas em uma área de Cerrado em Mato Grosso, 2010.

Das 20 espécies encontradas, 11 espécies apresentaram ausência de flor e fruto (Figura 3), sendo elas: Anarcadium humile, Anonna crassiflora, Brosimum gaudichaudii, Caryocar brasiliense, Diospyros burchellii, Dipteryx alata, Genipa americana, Hymenaea stigonocarpa, Mouriri elliptica, Talisia esculenta e Vitex montevidensis. A espécie Guazuma tomentosa apresentou apenas fruto. As espécies Acrocomia aculeata, Orbignya sp. e Solanum paniculatum apresentaram desde ausência e/ou presença de flor e/ou fruto. Nenhum indivíduo de Solanum lycocarpum apresentou 'apenas flor'. Os indivíduos de Inga edulis apresentavam apenas flor ou presença de flor e fruto, enquanto que os de Anona sp. apresentaram apenas frutos.

A ausência e presença de floração e frutificação foram semelhantes para 13 espécies com o que é encontrado na literatura (Tabela 2). Enquanto que, 05 espécies foram diferentes ao que a literatura especifica. De acordo com a literatura, 11 das 20 espécies apresentam floração na estação chuvosa.

Em comunidades florestais, os ritmos sazonais de floração e de frutificação podem mostrar padrões fenológicos característicos, os quais são relacionados com os fatores abióticos e bióticos da comunidade (Spina et al. 2001). Os fatores abióticos podem limitar diretamente a época de floração afetando a habilidade de produzir flores, ou indiretamente, afetando os vetores de pólen; podem também limitar a época de amadurecimento dos frutos (Rathcke e Lacey 1985).

De acordo com a literatura, as espécies encontradas na área de estudo (Tabela 2) apresentam uma sincronia de floração e de frutificação direcionada para uma determinada estação do ano, com a floração apresentando seu maior pico durante a estação úmida/quente e a frutificação durante a estação seca/fria.

Este padrão sugere uma sazonalidade na época de ocorrência das fenofases de floração e de frutificação em espécies do Cerrado, a qual estaria associada à variação climática durante as duas estações do ano (Spina et al. 2001). Tal padrão é citado na literatura como característico das florestas tropicais (Frankie et al. 1974; Matthes 1980; Morellato et al. 1989; Morellato 1991).

Das 20 espécies, 07 apresentam usos na alimentação, medicinal e outros; enquanto que 01 apresentou apenas uso alimentar e medicinal; e, 05 apresentam apenas uso alimentar (Tabela 3), o que indica elevado potencial de utilização das espécies nativas do Cerrado tanto para uso alimentar quanto medicinal. 
Tabela 3 - Tipos de usos das espécies nativas de plantas frutíferas em uma área de Cerrado em Mato Grosso, 2010.

\begin{tabular}{|c|c|c|c|c|}
\hline $\begin{array}{l}\text { Nome } \\
\text { Científico }\end{array}$ & Uso alimentar & Uso Medicinal & Outros tipos de usos & Fonte \\
\hline $\begin{array}{l}\text { Anonna } \\
\text { crassiflora }\end{array}$ & $\begin{array}{l}\text { Fruto consumido in } \\
\text { natura, potencial para } \\
\text { sucos e doces. }\end{array}$ & $\begin{array}{l}\text { Folhas, cascas e } \\
\text { sementes são usadas } \\
\text { contra diarreia. }\end{array}$ & - & $\begin{array}{l}\text { JÚNIOR. } \\
\text { S., } 2005 .\end{array}$ \\
\hline \multirow[t]{3}{*}{ Orbignya sp. } & $\begin{array}{l}\text { Semente (castanha) } \\
\text { comestível e produz } \\
\text { óleo rico em vitamina } \\
\text { e, serve para } \\
\text { margarina. }\end{array}$ & $\begin{array}{l}\text { Polpa em pó: anti- } \\
\text { inflamatório, } \\
\text { analgésico, laxante. }\end{array}$ & $\begin{array}{l}\text { Casca (mesocarpo) do } \\
\text { coco produz carvão } \\
\text { ativado para filtros, } \\
\text { coque siderúrgico, e } \\
\text { churrasco. }\end{array}$ & $\begin{array}{l}\text { POTT, A. } \quad \& \\
\text { POTT, A. J., } \\
\text { 1994. }\end{array}$ \\
\hline & $\begin{array}{l}\text { Leite de } \\
\text { equivalente ao leite } \\
\text { humano. }\end{array}$ & & $\begin{array}{l}\text { Folhas } \begin{array}{r}\text { para } \\
\text { artesanatos } \\
\text { chapéus) ecobertura }\end{array}\end{array}$ & \\
\hline & $\begin{array}{l}\text { Polpa em pó } \\
\text { alimentícia e } \\
\text { medicinal, rica em } \\
\text { amido, para substituir } \\
\text { farinhas e féculas } \\
\text { convencionais (trigo, } \\
\text { mandioca). Palmito. }\end{array}$ & & $\begin{array}{l}\text { de casas. Óleo usado } \\
\text { como lubrificante } \\
\text { industrial. }\end{array}$ & \\
\hline $\begin{array}{l}\text { Scheelea } \\
\text { phalerata }\end{array}$ & $\begin{array}{l}\text { Agua de coco, fruto e } \\
\text { sementes comestíveis } \\
\text { como farinha, óleo da } \\
\text { semente e palmito. }\end{array}$ & $\begin{array}{l}\text { Licor do caule } \\
\text { fortificante. }\end{array}$ & $\begin{array}{l}\text { Folha para coberturas } \\
\text { de casas, fibras para } \\
\text { cordas e chapéus. }\end{array}$ & $\begin{array}{l}\text { POTT, A. } \quad \& \\
\text { POTT, A. J., } \\
\text { 1994. }\end{array}$ \\
\hline $\begin{array}{l}\text { Acrocomia } \\
\text { aculeate }\end{array}$ & $\begin{array}{l}\text { Fruto comestível } \\
\text { (polpa) cozido com } \\
\text { leite, } \\
\text { farinhas. } \\
\text { Semente (castanha) } \\
\text { consumida crua ou } \\
\text { torrada, e óleo } \\
\text { comestível. } \\
\text { Palmito. }\end{array}$ & $\begin{array}{l}\text { Raiz diurética, } \\
\text { contra abcessos e } \\
\text { doenças } \\
\text { respiratórias. Óleo } \\
\text { laxante. }\end{array}$ & $\begin{array}{l}\text { Madeira em } \\
\text { construções, fibras } \\
\text { para artesanato e } \\
\text { cobertura de casas. } \\
\text { Sabões. }\end{array}$ & $\begin{array}{l}\text { POTT, A. \& } \\
\text { POTT, A. J., } \\
\text { 1994. }\end{array}$ \\
\hline $\begin{array}{l}\text { Anarcadium } \\
\text { humile }\end{array}$ & 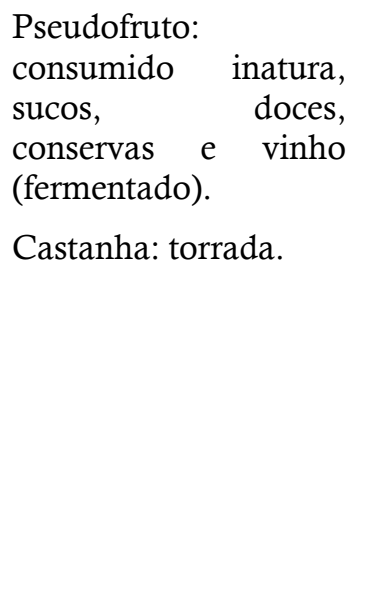 & $\begin{array}{l}\text { Casca: estimulante, } \\
\text { utilizada contra } \\
\text { inflamação de } \\
\text { garganta (gargarejo). } \\
\text { Raiz é purgante, } \\
\text { enquanto casca e } \\
\text { folha são contra } \\
\text { diarreia. Resina da } \\
\text { castanha serve para } \\
\text { queimar calos e } \\
\text { verrugas e acalmar } \\
\text { dor de dente e } \\
\text { doenças de pele, } \\
\text { como manchas e } \\
\text { espessamento. }\end{array}$ & $\begin{array}{l}\text { Casca serve para } \\
\text { indústria } \\
\text { plástico). } \\
\text { A cinza serniz, } \\
\text { pasta dental. }\end{array}$ & $\begin{array}{l}\text { POTT, A. } \& \\
\text { POTT, A. J., } \\
\text { 1994. }\end{array}$ \\
\hline
\end{tabular}


Tabela 3 - continuação...

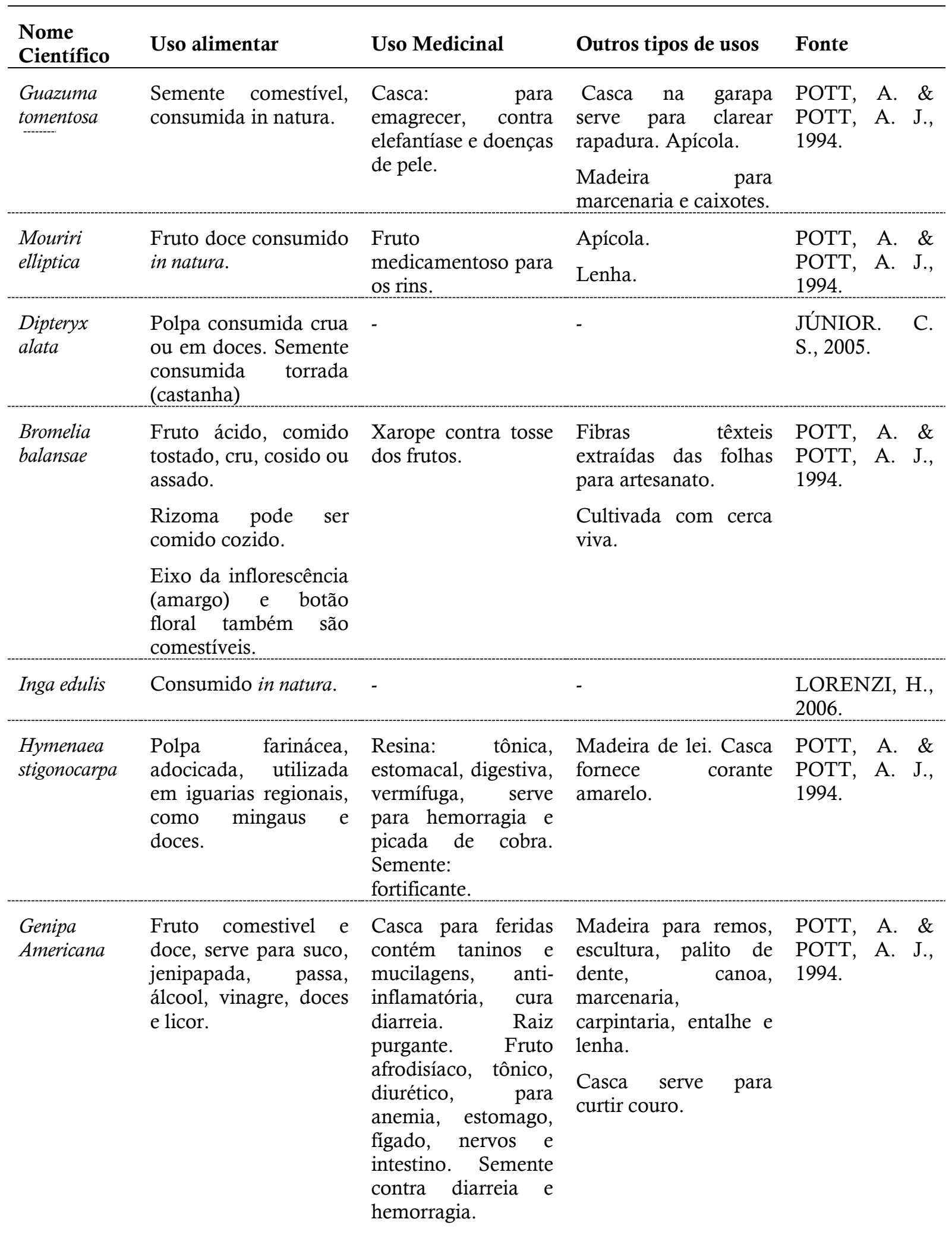


Tabela 3 - continuação...

\begin{tabular}{|c|c|c|c|c|}
\hline $\begin{array}{l}\text { Nome } \\
\text { Científico }\end{array}$ & Uso alimentar & Uso Medicinal & Outros tipos de usos & Fonte \\
\hline $\begin{array}{l}\text { Solanum } \\
\text { paniculatum }\end{array}$ & $\begin{array}{lll}\text { Fruto comido } & \text { em } \\
\text { omeletes ou } & \text { em } \\
\text { conserva. } & & \end{array}$ & $\begin{array}{l}\text { Fruto para curar } \\
\text { ressacas. Raiz, folha e } \\
\text { fruto verde contêm } \\
\text { jurubidina, resinas, } \\
\text { mucilagens e ácidos } \\
\text { orgânicos. srut } \\
\text { digestivo serve para } \\
\text { figado, hepatite e baço. } \\
\text { Folha cicatrizante e } \\
\text { febrifuga. Raiz } \\
\text { amarga, tornica, } \\
\text { digestiva, diurética, } \\
\text { usado contra anemia, } \\
\text { aperitiva, febrífuga, } \\
\text { laxante e estimula a } \\
\text { sudorese. Flor contra } \\
\text { resfriados, problemas } \\
\text { renais e diabetes. }\end{array}$ & - & $\begin{array}{l}\text { POTT, A. \& } \\
\text { POTT, A. J., } \\
1994 .\end{array}$ \\
\hline $\begin{array}{l}\text { Solanum } \\
\text { lycocarpum }\end{array}$ & $\begin{array}{l}\text { Fruto com polpa } \\
\text { amarelada utilizada } \\
\text { em doces caseiros. }\end{array}$ & 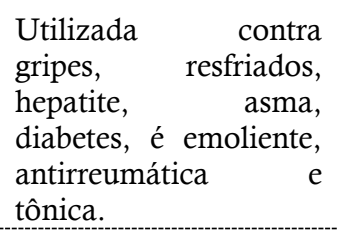 & $\begin{array}{l}\text { Produz } \\
\text { amarelados. }\end{array}$ & $\begin{array}{l}\text { JÚNIOR. C. } \\
\text { S., 2005. }\end{array}$ \\
\hline $\begin{array}{l}\text { Brosimum } \\
\text { gaudichaudii }\end{array}$ & $\begin{array}{l}\text { Fruto cru substitui } \\
\text { goma de masca. }\end{array}$ & $\begin{array}{l}\text { Casca e raízes usadas } \\
\text { contra vitiligo. É } \\
\text { expectorante, } \\
\text { depurativa, diurética e } \\
\text { desintoxicante. }\end{array}$ & $\begin{array}{l}\text { Seiva fermentada } \\
\text { pode ser consumida } \\
\text { como vinho. Raízes e } \\
\text { casca aromatizam o } \\
\text { tabaco. Madeira } \\
\text { utilizada ra na } \\
\text { marcenaria. }\end{array}$ & $\begin{array}{l}\text { JÚNIOR. C. } \\
\text { S., } 2005 .\end{array}$ \\
\hline $\begin{array}{l}\text { Diospyros } \\
\text { burchellii }\end{array}$ & $\begin{array}{l}\text { Fruto consumido in } \\
\text { natura, potencial para } \\
\text { sucos e doces. }\end{array}$ & - & - & $\begin{array}{l}\text { JÚNIOR. C. } \\
\text { S., } 2005 .\end{array}$ \\
\hline $\begin{array}{l}\text { Caryocar } \\
\text { brasiliense }\end{array}$ & $\begin{array}{l}\text { Fruto comestível, } \\
\text { cheiroso, consumido } \\
\text { cru, cozido em pratos } \\
\text { típicos (arroz com } \\
\text { pequi) e licores. } \\
\text { A fruta mais rica em } \\
\text { vitamina A. }\end{array}$ & $\begin{array}{l}\text { Óleo fortificante, rico } \\
\text { em vitamina A se } \\
\text { guardado no escuro. } \\
\text { Oleo para massagem } \\
\text { contra reumatismo. } \\
\text { Poupa contra gripe e } \\
\text { doenças respiratórias. } \\
\text { Licor estomacal. } \\
\text { Casca febrífuga e } \\
\text { diurética. }\end{array}$ & $\begin{array}{l}\text { Óleo da amêndoa } \\
\text { para cosméticos. } \\
\text { Madeira, corantes e } \\
\text { taninos. }\end{array}$ & $\begin{array}{l}\text { POTT, A. \& } \\
\text { POTT, A. J., } \\
1994 .\end{array}$ \\
\hline $\begin{array}{l}\text { Talisia } \\
\text { esculenta }\end{array}$ & $\begin{array}{l}\text { Consumido in natura. } \\
\text { Potencial para } \\
\text { extração de poupa } \\
\text { para sucos. }\end{array}$ & - & - & $\begin{array}{l}\text { LORENZI, H., } \\
2006 .\end{array}$ \\
\hline \multirow[t]{2}{*}{ Vitex cymosa } & $\begin{array}{l}\text { Consumido in natura. } \\
\text { Pouco apreciado. }\end{array}$ & $\begin{array}{l}\text { Folha medicinal, } \\
\text { tida } \\
\text { depurativa. }\end{array}$ & Madeira. & $\begin{array}{l}\text { LORENZI, H., } \\
2006 .\end{array}$ \\
\hline & & & & $\begin{array}{l}\text { POTT, A. \& } \\
\text { POTT, A. J., } \\
\text { 1994. }\end{array}$ \\
\hline
\end{tabular}


Vale salientar que, os recursos vegetais catalogados na área estudada são encontrados frequentemente em outras áreas de Cerrado, o que possibilita sua utilização como fonte de renda para as populações tradicionais, quilombolas, assentamentos rurais e pequenos produtores rurais.

É pertinente uma reflexão quanto à manutenção da diversidade biológica presente na área de estudo, especialmente considerando as graves e irreversíveis perdas ocasionadas ao Cerrado, que sofre fortes ações antrópicas, especialmente com o uso e ocupação por pastagens e monoculturas.

\section{AGRADECIMENTOS}

À Fundação de Apoio à Pesquisa do Estado de Mato Grosso (FAPEMAT) pela concessão de bolsa de iniciação científica Jr. ao terceiro autor (311797/2009) e pelo financiamento do projeto (673321/2008).

\section{REFERÊNCIAS}

ALMEIDA, S. P. DE \& SILVA, J. A. Piqui e buriti: importância alimentar para a população dos cerrados. EMBRAPA/CPAC, Planaltina (DF). 1994.

ALMEIDA, S. P. DE; PROENÇA, C. E. B.; SANO, S. M. \& RIBEIRO, J. F. Cerrado: espécies vegetais úteis. EMBRAPA/CPAC, Planaltina (DF). 1998.

BRANDÃO, M. Plantas produtoras de tanino nos cerrados mineiros. Informe Agropecuário, 6 (173):33-35. 1992.

CASTRO, A.A.J.F.; MARTINS, F.R.; TAMASHIRO, J.Y. \& SHEPHERD, G.H. How rich is the flora of Brazilian Cerrados? Annals of the Missouri in Botanical Garden 86: 192-224, 1999.

FRANKIE, G.F.; BAKER, H.G. \& OPLER, P.A. 1974. Comparative phenological studies of trees in tropical wet and dry forests in the lowlands of Costa Rica. Journal of Ecology 62(3): 881-913.

GUARIM NETO, G. 2001. Flora medicinal, populações humanas e o ambiente do cerrado. Horticultura Brasileira 19 (2): 204-205.

JEPSON, W. A disappearing biome? Reconsidering land-cover change in the Brazilian savanna. The Geographical Journal 171: 99-111, 2005.

KLINK, C.A. \& MACHADO, R.B. Conservation of the Brazilian Cerrado. Conservation Biology 19: 707$713,2005$.

LORENZI, H. Árvores Brasileiras. Plantarum. 1998.

LORENZI, H. Frutas Brasileiras e Exóticas Cultivadas: de Consumo in Natura. Plantarum. 2006.

MACEDO, J. F. Plantas corticosas do cerrado e sua utilização. Informe Agropecuário 15 (168): 33-37. 1991.

MATTHES, L.A.F. 1980. Composição florística, estrutura e fenologia de uma floresta residual do planalto paulista: Bosque dos Jequitibás (Campinas, SP.). Dissertação de Mestrado, Campinas, UNICAMP.

MORELLATO, L.P.C. 1991. Estudos da fenologia de árvores, arbustos e lianas de uma floresta semidecídua 
no sudeste do Brasil. Tese de Doutorado, Campinas, UNICAMP.

MORELLATO, L.P.C.; RODRIGUES, R.R.; LEITÃO FILHO, H.F. \& JOLY, C.A. 1989. Estudo comparativo da fenologia de espécies arbóreas de floresta de altitude e floresta mesófila semidecídua na Serra do Japi, Jundiaí, São Paulo. Revista Brasileira de Botânica 12: 85-98.

PASA, M.C.; SOARES, J.J. \& GUARIM NETO, G. 2005. Estudo etnobotânico na comunidade de Conceição -Açu (alto da bacia do rio Aricá-Açu, MT, Brasil). Acta Botânica Brasílica 19 (2): 195-207.

PAULA, J. E. DE \& ALVES, J. L. DE H. Madeiras nativas: anatomia, dendrologia, dendrometria, produção e uso. Fundação Mokiti Okada, Brasília. 1997.

POTT, A. \& POTT, V. Plantas do Pantanal. Embrapa. 1994.

PROENÇA, C.; OLIVEIRA, R. S. \& SILVA, A. P. Flores e frutos do cerrado. EdUnB, Brasília. 2000.

RATHCKE, B. \& LACEY, E.P. 1985. Phenological patterns of terrestrial plants. Annual Review of Ecology and Systematics 16: 179-214.

RATTER, J.A.; RIBEIRO, J.F. \& BRIDGEWATER, S. 1997. The Brazilian Cerrado: Vegetation and Threats to its Biodiversity. Annals of Botany 80: 223-230.

RIBEIRO, J. F.; SILVA, J. A. DA \& FONSECA, C. E. I. Espécies frutíferas da região do cerrado. Pp.159-189. IN: DONADIO, L. C.; MARTINS, A.B.G. \& VALENTE, J.P. Fruticultura tropical. FUNEP-FCAV/UNESP, Jaboticabal. 1992.

ROBOREDO, D.; MAIA, J.C.S.; OLIVEIRA, O.J. \& ROQUE, C.G. 2010. Uso de dois penetrômetros na avaliação da resistência mecânica de um latossolo vermelho distrófico. Engenharia Agrícola 30 (2): 307-314.

SHIKI, S.; SILVA, J. G. DA \& ORTEGA A. C. (Orgs.). Agricultura, meio ambiente e sustentabilidade do cerrado brasileiro. UFU, Uberlândia. 1997.

SILVA JUNIOR, M. C. 100 Árvores do Cerrado: Guia de Campo. Rede de Sementes do Cerrado. 2005.

SILVA, J. A.; SILVA, D. B.; JUNQUEIRA, N. T. \& ANDRADE, L. R. M. Frutas nativas dos cerrados. EMBRAPA/CPAC, Planaltina (DF). 1994.

SIQUEIRA, J.C. Utilização popular das plantas do cerrado. Ed. Loyola, São Paulo. 1981.

SPINA, A.P., FERREIRA, W.M. \& LEITÃO-FILHO, H.F. 2001. Floração, frutificação e síndromes de dispersão de uma comunidade de floresta de brejo na região de Campinas. Acta Botanica Brasilica 15: 349-368. 